\title{
A Filosofia da Educação nos cursos de Pedagogia do Brasil: da obrigatoriedade à dispensa progressiva ${ }^{1}$
}

\section{Eldon Henrique Müh² Elisa Mainardi ${ }^{3}$}

\section{Resumo}

A Filosofia nunca teve um papel relevante nos cursos de Pedagogia, mas sempre foi incluída no rol das disciplinas consideradas indispensáveis para a formação dos professores e, de modo especial, dos pedagogos. Na atualidade percebe-se, porém, sua dispensa progressiva com a justificativa da sua pouca utilidade na formação dos pedagogos. O presente texto analisa as razões dessa dispensa, destacando a responsabilidade da Filosofia e a visão reducionista da formação proposta no curso de Pedagogia pela situação criada. Por fim, apresenta algumas consequências desta dispensa e destaca a necessidade da reaproximação entre a filosofia e pedagogia para a promoção de uma formação pedagógica integral.

Palavras-chave: Filosofia; Pedagogia; Formação pedagógica.

\begin{abstract}
Philosophy has never played a relevant role in Pedagogy courses, but it has always been included in the list of disciplines considered indispensable for the training of teachers and, especially, of pedagogues. At the present time, however, it is perceived its progressive dispensation with the justification of its little use in the training of pedagogues. The present text analyzes the reasons for this exemption, highlighting the responsibility of philosophy and the reductionist view of the training proposed in the Pedagogy Course due to the situation created. Finally, it presents some consequences of this exemption and highlights the need for a rapprochement between philosophy and pedagogy for the promotion of integral pedagogical formation.
\end{abstract}

Keywords: Philosophy; Pedagogy; Pedagogical formation.

\footnotetext{
${ }^{1}$ Comunicação apresentada no II Congresso da Sociedade Brasileira de Filosofia e Educação, realizado na Universidade Estadual de Campinas, em 2016. O texto foi revisado e ampliado para esta edição.

${ }^{2}$ Licenciado em Filosofia, mestre e doutor em Educação pela Unicamp, professor do Programa de Pós-Graduação em Educação da Universidade de Passo Fundo (UPF).

${ }^{3}$ Licenciada em Pedagogia, mestre em Educação pela UPF, doutora em Educação pela Universidade de Ijuí (RS), professora da Faculdade de Educação da UPF.
} 
O educar e o filosofar identificam-se na medida em que ambos se esclarecem, se autojustificam, pensam o próprio pensamento e a própria ação.

Paviani, 2006, p. 20

presença da filosofia no currículo do curso da Pedagogia no Brasil
nunca foi muito representativa e sua função no desenvolvimento
do curso sempre foi pouco explícita. Porém, em razão da importância que a filosofia teve no desenvolvimento do pensamento ocidental, especialmente do pensamento católico, ela sempre foi incluída no rol das disciplinas dos "fundamentos", como base da formação dos pedagogos e dos professores. Na atualidade, no entanto, percebe-se uma progressiva dispensa da filosofia em suas diferentes modalidades disciplinares dos currículos do curso de Pedagogia e de quase todos os cursos de licenciatura. Para verificar esta tendência, basta consultar os currículos dos cursos e analisar as diretrizes nacionais que orientam as bases curriculares da Pedagogia e dos cursos de formação de professores. ${ }^{4}$ A reflexão sobre as razões desta progressiva dispensa da filosofia na pedagogia foi realizada por diversos filósofos e pesquisadores da educação, tanto brasileiros como estrangeiros. No presente texto, dado sua limitação, não será possível destacar as inúmeras contribuições que tais análises trazem na explicitação de tal situação. A questão que queremos enfrentar deste problema centra-se em três aspectos: a posição ideológica e conservadora da filosofia diante da pedagogia; o surgimento de mecanismos disciplinares mais eficazes de manipulação e controle da formação dos pedagogos, reduzindo a própria

\footnotetext{
${ }^{4}$ A Resolução n ${ }^{\circ} 2$ de julho de 2015, que define as Diretrizes Curriculares Nacionais para a formação inicial em nível superior (cursos de licenciatura, cursos de formação pedagógica para graduados e cursos de segunda licenciatura) e para a formação continuada, indica como disciplinas responsáveis pela formação pedagógica apenas três: Políticas Educacionais, Psicologia da Educação e Didática. Nenhuma menção à Filosofia da Educação ou a alguma outra disciplina de Fundamentos da Educação.
}

Filosofia e Educação [RFE] - Volume 9, Número 2 - Campinas, SP Junho-Setembro de 2017 - ISSN 1984-9605 - p. 7-22 
concepção de pedagogia; e, por fim, a dificuldade de comunicação entre a filosofia e a pedagogia na atualidade diante da perda da função justificadora da primeira e o reducionismo instrumental da segunda. Será uma reflexão centrada, em um primeiro momento, na dificuldade que a própria filosofia apresenta de fazer-se reconhecida pela prática que ela mesma desenvolve ou deixa de desenvolver sob a alegação de estar sendo dispensada. Em um segundo momento, ressaltamos o problema da visão reducionista de formação que hoje predomina na educação e na própria pedagogia como outra razão deste distanciamento. No final, apontamos para uma perspectiva que nos parece fecunda para o restabelecimento do diálogo entre filosofia e pedagogia.

\section{2 - Da presença compulsória à dispensa progressiva}

A filosofia sempre teve um papel mais ilustrativo do que formativo nos cursos superiores de formação dos pedagogos e dos professores. Inicialmente, nutrida pela orientação metafísica, ela apresentou uma postura dogmática e um matiz fundamentador da educação que servia, prioritariamente, para a justificação e legitimação da visão de mundo dominante, em detrimento do exercício de reflexão sobre os reais problemas que envolviam a formação dos indivíduos e a atuação dos educadores. Nessa condição, ela foi pródiga em oferecer um conjunto de concepções que deram sustentação à educação elitista e conservadora, utilizando-se de certo modelo de exercício reflexivo para sustentar projetos educativos hegemônicos e práticas pedagógicas autoritárias. Distanciada dos problemas cotidianos da educação, ela se fazia presente como um discurso disperso, eclético, muitas vezes meramente ideológico no processo formativo dos educadores e pedagogos. Posteriormente, com o surgimento da crítica moderna, ela procurou assumir uma posição menos dogmática, mas não deixa de manter sua posição de indicadora de lugar e juíza suprema dos saberes e fazeres humanos. Reconhecendo os limites da visão metafísica tradicional, a filosofia moderna concentrou-se na subjetividade, colocando no sujeito o poder da constituição

Filosofia e Educação [RFE] - Volume 9, Número 2 - Campinas, SP Junho-Setembro de 2017 - ISSN 1984-9605 - p. 7-22 
do conhecimento e da orientação de sua atividade no mundo. A filosofia do sujeito, porém, acaba sendo tão pretensiosa quanto a metafísica tradicional, pois ao afirmar o determinismo subjetivista, ela torna absoluto o poder do sujeito e não considera os fatores práticos que interferem em sua existência. De outra parte, com a expansão da mentalidade científica, a filosofia deixase influenciar pelo reducionismo cientificista, assumindo como tarefa principal, "a justificação epistemológica do empreendimento educativo e a defesa da utilização dos recursos técnico-científicos para sua boa condução" (Severino, 2007, p. 122).

A constatação sobre esta função conservadora e reprodutora da filosofia ou da filosofia da educação pode ser encontrada em diversos autores nacionais: Capalbo (1978), Saviani (1980) Albuquerque (1998), Flickinger (1998), Severino (2000;2007); Goergen (2000), Tomazetti (2003), Gallo (2007), Paviani (2008), Vieira (2010), Nobre (2012), Trevisan et alli (2014), Dalbosco (2008, 2016), dentre outros. Na literatura mundial podemos destacar as reflexões de Houssaye, Soëtard, Hameline, Fabre (2004), Meirieu (2002), Deleuze \& Guattari (1992), Gruschka (2014), além das contribuições de Dewey (1959), Rorty (1994) e Habermas (1989), para citar apenas alguns.

São análises de diferentes matizes que apresentam como ponto comum a constatação de que predominância da visão metafísica de filosofia tradicional e moderna- foi o principal impeditivo de uma real aproximação entre filosofia e pedagogia. Sua pretensão de ser a ciência fundamentadora ou de juíza suprema de todos os conhecimentos e de todas as práticas humanas, impediu que ela tivesse acesso ao processo concreto de como os conhecimentos e as práticas humanas são construídas e realizadas, incluindo a educação. A crítica à filosofia metafísica e as análises dos pensadores pósmetafísicos, oferecem farto material que expõe os limites a as contradições da visão tradicional da filosofia.

A questão que se coloca é que mesmo depois do desenvolvimento do pensamento pós-metafísico e de os filósofos reconhecerem a necessidade da filosofia assumir uma postura mais modesta em relação aos outros campos do saber e - no nosso caso, em relação à Pedagogia - ela continua apresentando

Filosofia e Educação [RFE] - Volume 9, Número 2 - Campinas, SP Junho-Setembro de 2017 - ISSN 1984-9605 - p. 7-22 
uma grande dificuldade de interagir e de se colocar na condição de "guardadora de lugar e de "interprete", como propõe Habermas (1989, p. 20).

$\mathrm{O}$ que se pode perceber é que historicamente a filosofia apresentou poucas iniciativas voltadas para uma relação de proximidade com as questões teóricas e práticas da educação. As obras filosóficas, de modo geral, falam "sobre" a educação, mas não tratam da presença da filosofia na prática cotidiana dos pedagogos. Iniciativas filosóficas que partem das experiências cotidianas dos educadores e que desenvolvem reflexões com os professores são muito raras. O que tem predominado são reflexões sobre as experiências práticas dos educadores que apontam as limitações e incongruências destas mesmas práticas. A filosofia continua a atribuir-se o papel de juíza e indicadora de lugar, considerando-se o "fundamento da educação" e fornecedora dos conceitos e das ideias que podem dar sustentação a uma prática educacional correta. Assumindo tal posição, ela acusa as práticas pedagógicas de serem destituídas de racionalidade e de não apresentarem um potencial transformador da realidade educacional.

Um dado factual desse distanciamento ou desta presença arrogante da filosofia diante da pedagogia pode ser constatado em duas concepções que são apresentadas como tarefas da filosofia da educação: primeiro, a concepção de que a filosofia tem como função possibilitar a aquisição da capacidade de refletir do educador e, segundo, a concepção de que as dificuldades educacionais decorrem da precariedade teórica dos educadores e da espontaneidade que predomina em seu agir cotidiano.

Para esclarecer a primeira concepção, podemos nos socorrer de diversos textos e materiais de filosofia de educação que manifestam em sua justificativa a pretensão de ser a promotora da reflexão, sob a alegação de que o professor, de modo geral, não desenvolve esta capacidade no trabalho que realiza cotidianamente. Sob uma visão ainda conservadora, a filosofia julga o fazer pedagógico cotidiano do educador como um fazer destituído de reflexibilidade, de racionalidade, conduzido apenas pelo hábito ou pelo senso comum. Sob a orientação de concepções ainda metafísicas, a filosofia não reconhece no pedagogo um intelectual que, conforme afirma Houssaye, 
“desenvolve ideias em relação aos seus próprios atos, produz finalidade ligada aos atos" (2004, p. 25). Sob este aspecto é esclarecedora a colocação da Paviani (2006, p. 12):

A filosofia, separada da pedagogia, assume a tarefa de justificar, pressupostos éticos e epistemológicos de processos educacionais. Procura exercer um papel crítico em relação à racionalidade instrumental e ao esclarecimento do pensamento pedagógico em si. Os sujeitos da educação e as teorias pedagógicas, o fazer e o agir educativos realizam-se dentro de uma dimensão filosófica global e não mais específica. Desenvolve-se uma determinação filosófica que sustenta a concepção educacional antes de qualquer reflexão típica de uma filosofia da educação.

Esta colocação de Paviani aproxima-se, no nosso entendimento, da crítica de Habermas acerca da filosofia, quando propõe que ela precisa perder a pretensão de ser a "indicadora de lugar" e de se apresentar como um "discurso fundamentador" (1989, p. 29). Ao se atribuir a tarefa de produzir no educador a capacidade de refletir e de possibilitar o seu pensar crítico, ela deixa de reconhecer que tal tarefa não é somente uma atribuição comum às ciências humanas e sociais, além de ser uma prática cotidiana do professor em seu exercício pedagógico. Portanto, a justificativa de sua presença na educação não pode se sustentar nesta tarefa exclusiva. Cabe-lhe sim, conforme aponta Habermas, ser uma interprete mediadora no exercício cotidiano do professor, recolocando em movimento a cooperação paralisada entre o fator cognitivo-instrumental com o moral-prático e o estéticoexpressivo (cf. 1989, p. 33). Nos termos de Paviani, ela precisa retomar seu papel de uma reflexão típica de filosofia e deixar de analisar a educação por categorias e teorias externas à Pedagogia e à própria filosofia.

Relativamente à segunda problemática - em que a filosofia aponta a precariedade teórica como um problema que limita a ação do pedagogo -, precisa-se avaliar com mais cuidado a especificidade da ação do professor em 
contextos formativos. A ação docente exige uma capacidade de mediação constante entre concepções teóricas e práticas. Não se trata de considerar que toda a prática é constituída de alguma forma de racionalidade, mas que a racionalidade presente em cada ação educativa apresenta potenciais críticos no que refere à contingência da própria ação prática.

O que deve ser levado em conta nesta circunstância são as dimensões próprias da ação pedagógica, tão bem destacadas por Houssaye (2004, passim): a ação, o enraizamento, as rupturas e a mediocridade ou precariedade do agir pedagógico. A ação é a condição de ser da pedagogia, o que a remete à necessidade da prática. Em pedagogia não se pode fazer economia da prática, pois ela só pode ser pensada em seu fazer. O que dá existência e consistência à pedagogia é a prática, pois é ela que sempre será a fonte do dizer. Mas a pedagogia não é meramente prática, pois se assim fosse não passaria de um mero fazer técnico. A pedagogia é também uma teoria da ação em desenvolvimento, ou seja, uma teoria praxiológica que visa compreender e qualificar a própria ação prática. Daí sua relação com o enraizamento, pois a pedagogia é de alguma forma testemunha de um tempo histórico e o pedagogo é portador das questões e das potencialidades de uma época determinada. Ou seja, o pedagogo nunca pode ser considerado um sujeito alheio a sua época por ser portador das questões educativas de sua época; nele se expressa a realidade intelectual, moral, social e cultural de determinado momento histórico. As rupturas revelam que a pedagogia é fruto de conflitos e contradições de diferentes momentos e contextos e o pedagogo é, em certa dimensão, produtor de algum tipo de ruptura com o momento presente. Em seu desejo de agir, o pedagogo resiste e destitui aquelas concepções e aquelas práticas que já não permitem seguir em seu fazer prático. Na busca de realização de uma nova educação, ele rompe com ideias e com práticas que considera improdutivas e ineficazes. Por fim, $a$ mediocridade ou precariedade, uma vez que a pedagogia e o pedagogo são frutos da própria incompletude da teoria e das limitações da prática. A história da educação e da pedagogia revela diversas propostas que fracassaram e outras tantas, que mesmo tendo vingadas por determinado 
tempo, manifestam inúmeras incoerências e contradições. Em pedagogia tudo é precário, incerto, mutável, humano, demasiado humano. Ela é uma ação que se configura teórica e praticamente como frágil.

De outra parte, não podemos deixar de ressaltar as limitações e as fragilidades da Pedagogia, que têm contribuído para a dispensa da filosofia e a instrumentalização da pedagogia. A história da Pedagogia revela que ela sempre apresentou dificuldade em se tornar um campo do saber e do fazer fundamentado em uma concepção abrangente e conceitualmente definida de ação. Nela predomina, de modo geral, o senso comum e as práticas solidificadas pela tradição. Sob a alegação de ser uma ação prática, muitos pedagogos tem insistido na ideia de que a aprendizagem ocorre pela prática e que a teorização não traz, de modo geral, uma contribuição efetiva para o desenvolvimento da prática. Em nome da experiência prática e da eficiência didática, a reflexão tem sido dispensada e a pedagogia reduzida a ao ensino de métodos e técnicas de ensino.

De modo mais pontual no Brasil, o curso de Pedagogia foi reduzido a um curso de formação de professores para a educação infantil e para os anos iniciais da educação fundamental, deixando de ser um curso de formação de pedagogos. Com isso, questões acerca do sentido e da finalidade da educação tornaram-se obsoletas e o pedagogo, enquanto responsável pela reflexão e a construção de conhecimentos sobre a formação humana e sobre o sentido do saber, está desaparecendo. Conforme destaca Dalbosco (2016, p. 49):

o prejuízo disso à Pedagogia é imenso, pois fez com que ele perdesse, no bojo desta transformação, sua dimensão prática no sentido ético, de preocupação de orientação de mundo, tanto dos docentes em exercício como dos futuros docentes.

Soma-se a isso, os problemas decorrentes da tendência de uma cultura da simplificação dos conhecimentos e práticas escolares pela introdução de pacotes pedagógicos de empresas de planejamento, gestão e avaliação. Apresentando projetos prontos e apostilas adequadamente organizadas para 
atender demandas próprias do mercado e da sociedade concorrencial, empresas e especialistas tem invadido o espaço da formação de docentes sob a promessa de uma formação mais rápida e menos exigente. O preço disso tudo é o empobrecimento da experiência formativa dos pedagogos e a exclusão do processo de sua formação de todas aquelas atividades que exigem reflexão, criatividade, dedicação, esforço pessoal e formação integral do professor.

3 - Sobre a necessidade da filosofia na educação no curso de Pedagogia Percebemos na breve análise acima que a filosofia e a filosofia da educação contribuíram no Brasil, com raros momentos de exceção, para o desenvolvimento da subserviência da formação docente aos ditames da cultura dominante, promovendo raramente a visão crítica sobre os mecanismos da manipulação de tal formação. Com o surgimento de mecanismos e de disciplinas mais eficazes nesta tarefa - como a psicologia, a sociologia, as neurociências - ela deixa de ter prioridade nesta função legitimadora. Ao se desenvolver como um saber ideológico de reprodução da ordem existente, ela perdeu um espaço precioso para seu desenvolvimento como saber teórico e prático da educação.

Diante deste quadro, perguntamos: Qual é possibilidade de a filosofia reassumir um papel de algum protagonismo na educação e na formação do pedagogo na atualidade? Qual é esse papel e que exigências devem ser estabelecidas para que essa tarefa possa ser realizada? Afinal, qual é o espaço que ainda cabe à filosofia da educação na formação de pedagogos e de docentes das outras áreas?

Para responder estas questões, a filosofia precisa estabelecer, inicialmente, um diálogo com os pedagogos, assumindo uma postura humilde, cuidando de não forçar a mera transferência de suas preocupações sobre a educação para os pedagogos ou de culpa-los pela perda de seu poder fundamentador. Em outros termos, os filósofos da educação devem cuidar para não assumirem "o lugar dos pedagogos" ou de quererem novamente 
estabelecer as bases do conhecimento pedagógico, ao oferecer alternativas gestadas por reflexões privadas no campo filosófico para o campo pedagógico. O desafio do filósofo é o de colocar-se ao lado do pedagogo e dialogar sobre a possibilidade que a filosofia tem de contribuir na formação dos pedagogos e no exercício de sua função pedagógica e docente.

As reflexões de muitos filósofos apontam que a prática filosófica precisa ser revista, pois nossos discursos sobre a educação e a pedagogia pouco repercutem na formação e prática dos educando e professores. Por vezes achamos que esta situação está mudando, mas as manifestações e os estudos acerca da importância da filosofia na formação e na ação educativa revelam a sua progressiva dispensa, exatamente no momento em que a filosofia atinge um significativo grau de qualificação no Brasil. Como explicar esta tendência? Vamos apontar algumas constatações sobre o tema.

Em primeiro lugar, cabe destacar que a filosofia carece do problema de não saber tornar-se pública e assumir uma linguagem mais próxima da linguagem cotidiana e mais atrelada aos modos e formas de manifestação do saberes dos indivíduos. Do ponto de vista da educação, ela tem dificuldade de transformar os problemas que os educadores enfrentam no cotidiano escolar em questões ou problemas filosóficos.

A filosofia tem duas atividades a desempenhar na educação: a primeira que implica em examinar a realidade educacional e promover a imaginação criativa dos concernidos. Trata-se de aprender, no primeiro aspecto, a filosofia e a pedagogia já existentes como recurso para o entendimento da realidade e sua configuração. A segunda, que trata de sensibilizar os indivíduos para a abertura diante da multiplicidade de manifestações que a realidade pode oferecer. Para tanto, a filosofia, assim como a pedagogia, precisa retomar sua condição de reflexão e de formação do indivíduo pela investigação partilhada entre ambas. Trata-se de transformar a filosofia em uma prática pedagógica, fazendo com que sejam explicitados os aspectos pedagógicos que se fazem presentes nas diferentes experiências educativas promovidas pela pedagogia.

Filosofia e Educação [RFE] - Volume 9, Número 2 - Campinas, SP Junho-Setembro de 2017 - ISSN 1984-9605 - p. 7-22 
Neste ponto, consideramos que uma contribuição importante que pode auxiliar na compreensão do papel da filosofia diante da pedagogia, é a concepção de Habermas quando atribui à filosofia a tarefa de se tornar interprete das questões que surgem cotidianamente no mundo da vida, no caso, no cotidiano da educação:

Assim, a filosofia poderia actualizar sua relação com a totalidade em seu papel de intérprete voltado para o mundo da vida. Ela poderia, ao menos, ajudar a recolocar em movimento a cooperação paralisada, como um móbile teimosamente emperrado, do fator cognitivo-instrumental com o moral prático e o estético expressivo (HABERMAS, 1989, p. 33).

Para exercer a função de interprete e mediadora, ela é desafiada a entabular conversações entre os saberes do mundo da vida - mundo do cotidiano educacional - e os saberes provenientes das diferentes áreas do saber, procurando promover a integração dos diferentes domínios da ação humana. Relativamente à educação, isso implica em assegurar a abertura permanente a todos os saberes e ações na busca de justificativas e formas de ação comunicativas de todos os envolvidos com o processo educativo.

Além disso, a proposta de Habermas (1989) de "transformação da filosofia na perspectiva da teoria da ação comunicativa como ciência reconstrutiva" é provocativa ao propor a reformulação da relação teoria e prática através da reaproximação entre conhecimento e a condição humana. Ao conferir autoridade epistêmica aos saberes cotidianos e "à comunidade daqueles que cooperam e falam uns com os outros" ele aponta para a necessidade que se leve em consideração, como ponto de partida de toda a reflexão - teorização-, a vida concreta de educadores e educandos e a prática pedagógica que estes desenvolvem cotidianamente. Isso porque, nos termos do próprio autor, elas não manifestam apenas "hábitos de vida" ou "meras práticas", mas possibilidade de fundamentação" e "práticas de justificação sociais" (cf. HABERMAS, 1989, p. 33-34).

Filosofia e Educação [RFE] - Volume 9, Número 2 - Campinas, SP Junho-Setembro de 2017 - ISSN 1984-9605 - p. 7-22 
Ressalta-se que a tarefa de interprete e de mediadora da filosofia não se reduz, porém, à análise do mundo da vida e do processo de sua reprodução da educação cotidiana. Ela não pode deixar de continuar a se ocupar reflexivamente com a totalidade da cultura e com as outras dimensões a que a educação sempre está vinculada: questões antropológicas, epistemológicas e axiológicas. Para compreender a educação, ela não pode dispensar à reflexão sobre a condição antropológica de ser humano como ser que apreende e ensina, sobre as condições racionais, científicas ou não, que sustentam diferentes concepções pedagógicas e sobre a destinação da educação quanto aos seus princípios e fins. No entanto, todas estas tarefas só encontram sentido e unidade quando atreladas a prática comunicativa cotidiana de pedagogos e filósofos. Para que isso ocorra, é preciso que se estabeleça uma relação de cooperação no desenvolvimento de reflexões acerca das implicações destas dimensões nas concepções e nas práticas pedagógicas cotidianas. Destas reflexões surgirão as interpretações cognitivas, as expectativas morais, as expressões e valorizações que darão sustentação a ação de pedagogos e filósofos. Serão sempre saberes e valores frágeis, precários, provisórios, que não só revelarão a fragilidade e a precariedade da educação diante das ciências e das demais áreas do saber, mas da própria condição humana. Mas desta experiência de precariedade se produzirá a necessidade de uma aproximação cada vez maior entre pedagogia e filosofia. Como sabemos a pedagogia só surge quando a educação se torna problemática, da mesma forma que a filosofia nasce quando a crise se instala. Acreditamos que é no momento da crise que a filosofia pode melhor contribuir para que a pedagogia possa renascer das cinzas e ela mesma possa expressar seu papel fundamental para a Pedagogia. Para tanto, filosofia e pedagogia precisam andar lado a lado, nem acima, nem abaixo uma da outra. 
4 - À guisa de conclusão: reaproximação entre práxis filosófica e práxis pedagógica.

A dispensa da filosofia, ainda que justificada historicamente pela sua postura imperial e seu descaso no trato das questões do cotidiano da educação, poderá trazer consequências ainda mais problemáticas para a educação. Não se trata meramente de um reclamo dos filósofos por estarem perdendo um espaço importante de sua atuação, mas de um risco efetivo de a educação perder o sentido de sua razão de ser, qual seja, a promoção da humanidade nos homens.

O abandono da filosofia no campo da educação representa, em última instância, o abandono da pergunta sobre o sentido da existência humana e sobre o destino que queremos dar ao mundo. Significa abandonar questões que historicamente preocuparam a humanidade e que a levarem a construir todo o arcabouço de saberes que definimos como tradição. Significa eliminar o diálogo crítico com a ciência, com a política, com a ética e com o próprio senso comum. Significa, por fim, abandonar a pergunta sobre nossa origem e nossa destinação.

Diante disso, o desafio urgente que se apresenta para os filósofos e educadores é o de encontrar formas concretas e efetivas de reaproximação e de convivência produtiva. Para tanto, a filosofia tem o desafio de se tornar mais comunicativa e mais atenta às questões que se fazem presentes na prática cotidiana dos professores, de modo especial, dos pedagogos. A pedagogia, por seu turno, não pode dispensar facilmente a filosofia sob o risco de tornarse uma prática meramente adaptativa e reprodutiva dos educadores e educandos à situação vigente.

A necessidade da reaproximação entre filosofia e pedagogia é urgente. A precariedade da pedagogia diante das concepções reducionistas de educação que começam a se impor se assemelha muito à precariedade da filosofia diante do crescimento de racionalidade sistêmica e de mundo administrado. Por isso, ambas precisam se alimentar reciprocamente, considerando a necessidade de uma ação permanente sobre a condição precária da vida humana no mundo. Trata-se de reforçar mutuamente o 
exercício do diálogo crítico e a preocupação comum de desenvolver a humanidade possível entre educadores e educandos pela práxis reflexiva sobre o processo formativo que ocorre cotidianamente. Para tanto, a filosofia precisa deixar de lado seu pressuposto ideológicos de ser possuidora do conhecimento fundamentador e explicitador dos pressupostos da pedagogia, para colocar-se na condição de colaboradora na introdução da prática do filosofar na atividade pedagógica. De parte da Pedagogia, cabe-lhe reconhecer a indispensabilidade do exercício reflexivo no desenvolvimento da prática pedagógica como exigência para sua qualificação. Tal reconhecimento mútuo pode potencializar a relação e torna-la eficaz na perspectiva da formação humana e da práxis emancipadora.

A tarefa comum de filósofos e pedagogos é de promover o retorno da pedagogia ao exercício do pensar a educação e da filosofia de se tornar um pensar desde o lugar da pedagogia. Em outros termos, é preciso não esquecer que existem elementos comuns e identificadores entre filosofia e pedagogia que exigem a manutenção de sua relação enquanto práxis comum, concomitantemente filosófica e pedagógica. Pois, conforme afirma com propriedade Paviani (2006, p. 21), "nada mais educativo do que a própria experiência de filosofar".

\section{Referências}

ALBUQUERQUE, M.B. Filosofia da Educação: uma disciplina entre a dispersão de conteúdos e a busca da identidade. Perspectiva, 16(290: 45-61). jan./jun.1998.

CAPALBO, C. As ideias filosóficas no Brasil. São Paulo: Convívio, 1978.

DALBOSCO, C. A. Pedagogia filosófica: cercanias de um diálogo. São Paulo: Paulinas, 2007.

DALBOSCO, C. A. Filosofia da Educação como forma de vida e orientação de mundo.

In: SEVERINO, A.J.; LORIERI, M.A.; GALLO, S.(Orgs.). O papel formativo da filosofia. Jundiaí-SP: Paco Editorial, 2016, p. 45-68. 
DELEUZE, Gilles e GUATTARI, Félix. O que é a filosofia? Rio de Janeiro: Ed. 34,1992.

DEWEY, J. Democracia e educação. São Paulo: Ed. Globo, 1959.

HABERMAS, J. Consciência moral e agir comunicativo. Rio de Janeiro: Tempo Brasileiro, 1989.

HABERMAS, J. Verdade e justificação: ensaios filosóficos. São Paulo: Loyola, 2004.

GALLO, S.. Filosofia da Educação no Brasil do Século XX: da crítica ao conceito. Eccos. Revista Científica, v. 9, p. 261-284, 2007.

GOERGEN, P. L. Competências docentes na educação do futuro: anotações sobre a formação de professores. Nuances, Presidente Prudente, n. 6, v. 6, 2000, p. 1-9.

MÜHL, E. H. Habermas e a educação: racionalidade comunicativa, diagnóstico crítico e emancipação. Educação e Sociedade, Campinas, v.32, n. 117, p. 893901, out-dez, 2011.

NOBRE, M. Da "formação" às "redes": filosofia e cultura depois da modernização. Cadernos de Filosofia Alemã. São Paulo, n. 19, 2012, p. 13-36. PAVIANI, Jayme. Filosofia e educação, filosofia da educação: aproximações e distanciamentos. In: DALBOSCO, C.A; CASAGRANDA,E.A.; MÜHL, E.H. Filosofia e Pedagogia: aspectos históricos e temáticos. Campinas, SP: Martins Fontes, 2006.

RORTY, Richard. A Filosofia e o Espelho da Natureza. Rio de Janeiro: Relume-Dumará, 1994.

SAVIANI, Dermeval Saviani. Contribuições da filosofia para a educação. Em aberto, Brasília, ano 9, n.45, p.3-18, jan./mar. 1990.

SAVIANI, D. Educação: do senso comum à consciência filosófica. São Paulo: Cortez, 1980.

SEVERINO, Antônio Joaquim. A contribuição da filosofia para a educação. Em aberto, Brasília, ano 9, n.45, p.19-25, jan./mar. 1990.

SEVERINO, A.J. A filosofia da educação no Brasil: esboço de uma trajetória. In: GHIRALDELLI, P. (Org.) O que é filosofia da educação? Rio de Janeiro: DP\&A, 2000, p. 265-326.

Filosofia e Educação [RFE] - Volume 9, Número 2 - Campinas, SP Junho-Setembro de 2017 - ISSN 1984-9605 - p. 7-22 
SEVERINO, A.J. Educação, sujeito e história. São Paulo: Olho Dágua, 2007. TOMAZETTI, E.M. Filosofia da educação: um estudo sobre a história da disciplina no Brasil. Ijuí: Editora Unijuí, 2003.

VIEIRA, M. Filosofia da educação na formação do pedagogo: discurso de autonomia e fabricação de heteronomia. São Paulo (Tese de doutorado em Educação): Universidade de São Paulo, 2010. 